\title{
RESEARCH: A RELIABLE WAY TO REALITY Anjana Bhattarai*
}

\section{ABSTRACT}

The word itself tells us that re-search stands for an act of observing something repeatedly in order to find out some new information is research. Highlighting this fact Grinnell (1993) states:

\begin{abstract}
The word research is composed of two syllables, re and search. The dictionary defines the former as a prefix meaning again, anew or over again and the latter as a verb meaning to examine closely and carefully, to test and try or to probe. Together they form a noun describing a careful, systematic, patient study and investigation in some field of knowledge undertaken to establish facts or principles. Research is a structured inquiry that utilises acceptable scientific methodology to solve problems and create new knowledge that is generally applicable (as cited in Kumar, 2005:7).
\end{abstract}

\section{INTRODUCTION}

However, research can be viewed from three different levels. Firstly, in general way it is a search of information and knowledge. Understanding research at the basic level is getting answer to certain questions. In our day to day life we are asking questions to ourselves or to others to attain some kind of information. For example, at present the very common issue is of banda (closure) in Nepal. We may have to go somewhere and we suddenly find that there is a closure. At that moment, we first start to think that it may be because of an accident, kidnap, political pressure, etc. Then we enquire others to reach the real cause. In this short action we become busy in the process of observation, hypothesis formation, hypothesis testing and reaching the conclusion. In this way, research is not always high sounding, technical, complex, and involving statistics or computers. It is a process of finding out the reality.

Secondly, to conceptualize it, its characteristics can be focused because a scientific and systematic search for new knowledge, information on a specific topic is research. Two major characteristics of research- scientific nature and systematic process - must be reflected in it. Scientific nature always emphasizes on the spirit, principle and methodology of science. Similarly systematic process stresses on carrying out each of its steps in a hierarchical order, i.e., following the in-built system. Scientific spirit always encourages the researcher not to take any information (or method) for granted or not to believe in dogmas. Because of this a researcher has to collect enough evidence before presenting explanation or prediction of any information (examples). Scientific principles guide the researcher to be objective, economic, exhaustive, consistent and explicit. Scientific methodology prepares the researcher to carry out the research step-bystep. Methodology incorporates the system of activities like preliminary observation, identification of a problem, setting objectives, formulating hypothesis, preparing research tools, collecting data, analyzing data and concluding the whole study. 
To prove the scientific spirit and the principle of objectivity a research report should be full of reference citations, that is, to support the researcher's perspective information should be drawn from different sources and included in the presentation of report.

Citation refers to the borrowing of ideas and words from different existing sources which help to clarify the researcher's view point. This borrowing must be acknowledged by mentioning the writer's surname, year of publication and page no. so that the borrowing can be looked at in original text in need.

If the researcher is interested to find out professional activities of Nepali teachers of English, first he has to discuss the concepts like profession, professionalism and the activities accomplished by a professional. For this he can say professionalism emphasizes on discharging one's duty whole-heartedly. To support his view if he draws information from existing literature like Ur (2002) presents it more clearly.

According to Ur (2000, p. 389), "Professionalism means preparing oneself to do a competent job through learning."

It becomes citation but if the researcher presents Ur's words as his own without acknowledging her then it becomes plagiarism.

Citation must not be equated with plagiarism which is an academic theft (If the researcher does not mention the source and presents the information as his own, the idea becomes plagiarised and if he mentions the source that becomes cited). Plagiarism is a dangerous disease rapidly spreading at present. Regarding this Sharma (2007: 134) writes, "Plagiarism has been troubling academic world since long. With the invention of electronic resources like internet in recent times, it has become easier and more accessible." Hence, we must not commit this crime. Instead, we must cite the sources honestly.

The third way of viewing research is in terms of its methodology. Research is the investigation of truth which follows a systematic methodology of identifying a question/problem; collecting data and analyzing and interpreting the collected data. To support these major activities there occur many other activities in the whole period of research. Although each activity looks clear and distinct, in practice that does not happen. Some activities are accomplished simultaneously, some latter activities may help to modify the earlier activities. This reality is more clearly presented by Dunferd (2004: 46).

\footnotetext{
Most prescriptions for the research process describe it as a series of sequential steps, beginning with the identification of a research problem or question, then moving (via a review of the existing literature) to a statement of a conceptual model, data collection and finally to analysis and a conclusion. However, this is a somewhat idealized statement of the process. In reality, the process is often much less clear, because research is a learning and iterative process in which 'later steps' clarify 'earlier steps', allowing the latter to be modified or at least stated more clearly. For example, the specific focus of the research will often be fine-tuned in the process of carrying out the research, leading to a rephrasing of the topic in later drafts.
}

In summary, we can say research is an investigation of reality which follows the scientific and systematic process in the whole activity. The 
investigated truth is the most reliable one but that can always be verified, i.e. the truth is never final.

\section{IMPORTANCE OF RESEARCH}

The importance of research is more visible in the fields of health and technology than any others. The non-stop research studies carried out in these fields have brought many changes, improvement in the existing situation, for example, various types of medicines for different diseases and new models of devices like laptops, mobiles, television and many more. Not only this but also only because of research has it been possible for humans to reach the moon. Human beings are still eager to find out unexplored facets of the universe.

In the field of teaching and learning also scholars like Pavlov and Skinner have explored learning theories by carrying out research. At present also scholars, teachers and academicians are busy in research focusing on issues like improving teaching techniques, learning materials, learning environment, helping differently abled children and several other areas of enquiry.

To be specific, research is invaluable in widening our knowledge, in laying the foundation for the further research, in providing evidences to consolidate the existing theory or to formulate new theory, in guiding the critical and empirical examination and evaluation of the professional facts, in identifying existing professional challenges, in making decisions for formulation of new policies and guidelines, in providing effective professional services which help in improving and reforming the existing situation. Research is important because it activates the researcher.

\section{CONCLUSION}

Research, a kind of reflection, helps to cultivate discipline on the professionals in which they always ask question to themselves before accepting some information as true and try to transfer the same habit of asking questions to their students. Professionals become aware of the principle and methodology of research and utilize them whenever they need and can. Similarly when they face challenges in their day to day professional life, they become active in finding out the root of challenges and solving them. In this way research is the most reliable way to explore and reach the conclusion of most of the professional problems.

\section{WORKS CITED}

Cohen, L., Manion, L. and Morrison, K. (2007). Research methods in education. Routledge, London.

Dunford, R. (2004). Developing a research proposal. In Burton, S. and Steane, P. (Eds.). Surviving your thesis (pp. 46-54). Routledge, London, Newyork.0 
Grinnel, R.J. (ed.). (1993). Social work, research and evaluation. (4 ${ }^{\text {th }}$ ed.), F.E. Peacock Publishers, Illinois.

Kumar, R. (2005). Research methodology. Darling Kindersley, India.

Sharma, B.K. (2007). Plagiarism among University students: Intentional or accidental? Journal of NELTA. 12/ ${ }^{1 / 2}, 134-141$.

Ur, P. (2002). The English teacher as professional. In J.C. Richards and W.A. Renandya (Eds.). Methodology in language teaching. pp. 388-392. 